\title{
Solvent-Free Membrane Extraction of Volatile Fatty Acids from Acidogenic Fermentation
}

Victoria Outram and Yue Zhang

Faculty of Engineering and Physical Sciences, University of Southampton, Southampton, SO17 1BJ, UK. 


\section{Abstract}

Diversification of anaerobic digestion into higher value products, namely volatile fatty acids (VFAs), is receiving interest. One of the biggest challenges with this is recovery of the VFAs. Membrane extraction can be used, and a novel process configuration using a non-porous silicone membrane and water for an extractant is proposed here. This process would enable the reduction in the number of downstream unit operations compared to other membrane extraction processes. Selective recovery in favour of longer chain VFAs was demonstrated. Testing with a synthetic solution resulted in an overall mass transfer coefficient of $0.088 \mu \mathrm{m} \mathrm{s}^{-1}$ for butyric acid, and 0.157 $\mu \mathrm{m} \mathrm{s}^{-1}$ when fermentation broth was used. This indicates this process is not hindered by fouling, but improved somehow. Although the preliminary economic analysis showed this process to require a larger membrane area compared to porous membrane alternatives, it also has a significantly reduced cost associated with the extractant.

\section{Graphical Abstract}

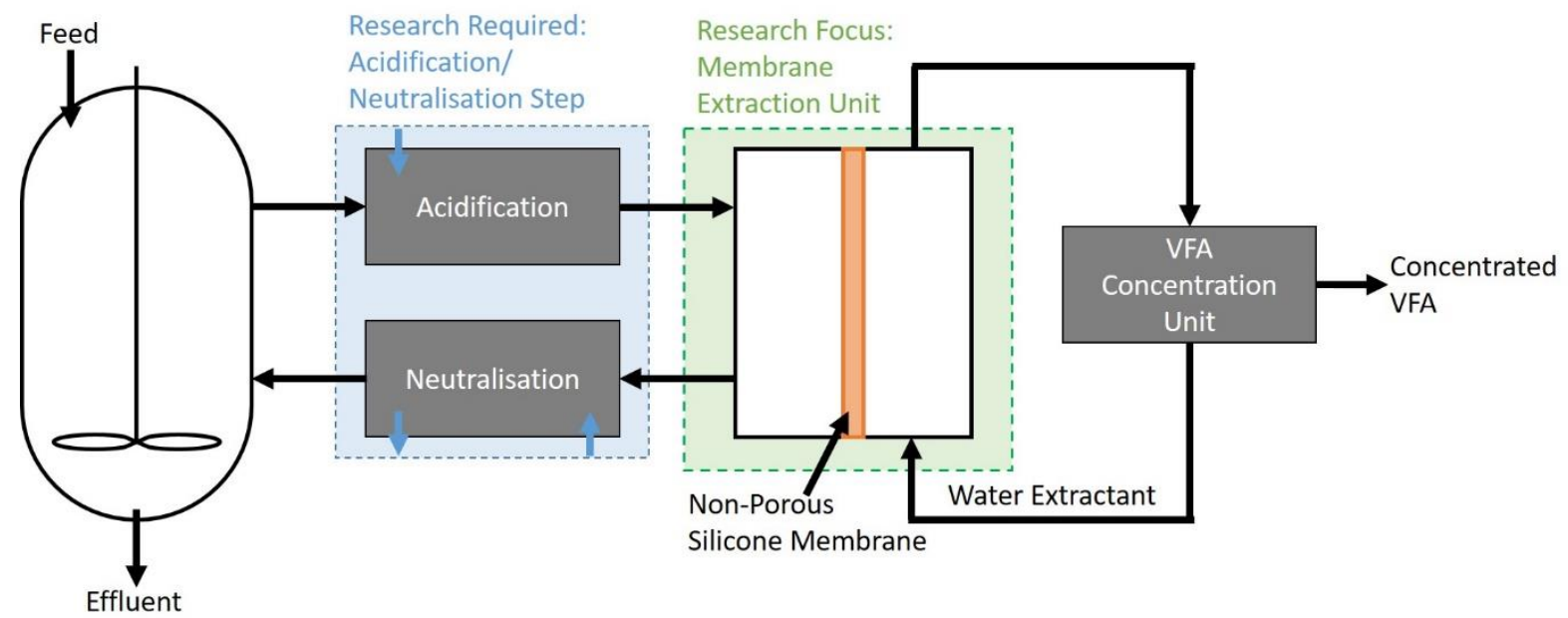

\section{Highlights}

- Product recovery of VFAs from acidogenic fermentation is difficult

- A simplified membrane extraction using a silicone membrane and water was successful 
- A silicone membrane demonstrated no negative impact from fouling

- An external membrane extraction unit is required to facilitate $\mathrm{pH}$ 2-3 for mass transfer

\section{Keywords}

Volatile Fatty Acids, Acidogenic Fermentation, Membrane Extraction, In Situ Product Recovery 


\section{Introduction}

Anaerobic digestion (AD) technology is a staple of waste treatment processes, producing biogas (methane and carbon dioxide) for renewable energy and organic waste stabilisation (Kleerebezem et al., 2015). Even though $A D$ is a well-developed technology it can experience various instabilities, largely associated with different feedstocks. For example, protein-rich feedstocks have a high nitrogen content which is transformed into ammonia. This inhibits the methanogens present, causing a build-up of volatile fatty acids (VFAs) (Chen et al., 2008). VFAs can be used in the chemical industry, as building block chemicals (Straathof, 2014), but also as feedstocks for bioprocesses such as polyhydroxyalkanoate (PHA) production (Kleerebezem et al., 2015; Tao et al., 2016). Production of mixed VFAs through mixed-culture fermentation under anaerobic conditions is known as acidogenic fermentation (AF) (Lee et al., 2014).

One of the big challenges with VFA production via AF is product separation and recovery. The recovery of organic acids is typically $30-40 \%$ of the processing cost (Bekatorou et al., 2016), therefore economically viable recovery processes need to be developed. It is desirable to integrate the primary separation step with the fermentation, through in situ product recovery (ISPR) (Zhou et al., 2018). This is to ensure that the VFAs are not further degraded, and ensure optimum production (Yesil et al., 2014). Separation is complicated due to the low VFA concentration ( $<10$ wt.\%) with high solubility in water (Singhania et al., 2013), and the complex fermentation broth with high solid content (Zhou et al., 2018). Several methods have been proposed for recovery of VFAs from AF: nanofiltration (Longo et al., 2015; Zacharof et al., 2016), liquid-liquid extraction (Alkaya et al., 2009; Reyhanitash et al., 2016), adsorption (Rebecchi et al., 2016; Reyhanitash et al., 2017), electrodialysis (Jones et al., 2015; Tao et al., 2016) and membrane extraction (Plácido and Zhang, 2017a; Yesil et al., 2014).

Membrane extraction is a well-documented ISPR method for single carboxylic acids from pure culture fermentation. Based on the data collated by Stark and von Stockar (2003) and Van Hecke et 
al. (2014), between 1993 and 2013, membrane extraction accounted for 24\% of ISPR research into acids. Reactive liquid-liquid extraction, ion-exchange adsorption and electrodialysis each accounted for $18 \%$ of the research. The typical membrane extraction setup used is a two membrane system, whereby the first membrane removes the acid from fermentation broth via an extractant in a diluent. The extractant then passes across a second membrane and contacted with a sodium hydroxide solution. This regenerates the extractant to maximise the transfer of acid out of the fermentation broth. The acid product is then present as a sodium salt in the aqueous phase (Schlosser et al., 2005). The downside to this is that the sodium salt will need to be acidified with a mineral acid to achieve a product in the free acid form, therefore two chemicals will be consumed during this process. It also produces a mineral salt that will need to be disposed of, or a use found for it. Alternative methods of extractant regeneration methods such as (vacuum) distillation have been proposed (Saboe et al., 2018). 


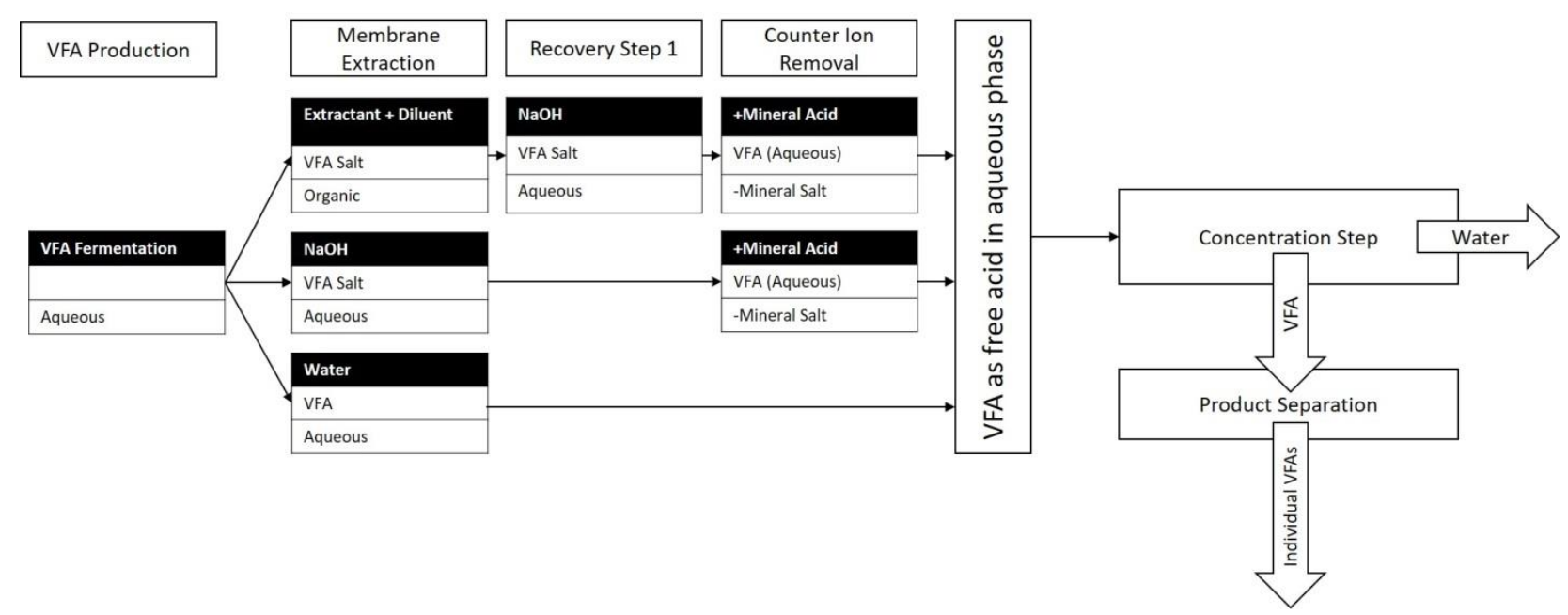

Figure 1: A high level process schematic for various membrane based recovery methods, with the intention of individual VFA recovery.

Membrane extraction has since been applied as a recovery method of mixed VFAs from AF. Plácido and Zhang (2017a) followed the "more traditional" membrane extraction process using trioctylamine (TOA) with octanol (top route, Figure 1), and compared the process with in situ esterification as a means of product recovery. Membrane extraction could successfully remove $50 \%$ of total VFA from a synthetic solution (initial concentration $100 \mathrm{~g} \mathrm{VFA} \mathrm{L}^{-1}$ ) in 2 hours, with a greater percentage recovery of the more non-polar (hydrophobic) acids. Plácido and Zhang (2017a) state that membrane extraction is better suited for continuous recovery than liquid-liquid extraction.

Membrane extraction of VFAs from anaerobic fermentation has also been investigated by a group at Marmara University, Turkey (Aydin et al., 2018; Tugtas, 2014; Yesil et al., 2014). They remove the extraction step from the process, instead applying the second membrane extraction step directly to the fermentation, therefore using an aqueous-based extractant, (middle route, Figure 1). In the initial work, the pores of the hydrophobic membrane were not wetted, therefore remaining airfilled, and the relative volatility of the VFAs compared to water providing the means of separation selective for VFA. The acids react with sodium hydroxide on the permeate side, to form a sodium salt, ensuring a constant concentration gradient to drive the mass transfer. Aydin et al. (2018) 
describe this method as vapour permeation. Using a hydrophobic membrane should keep the two aqueous solutions separate, therefore this is a possible recovery method (Tugtas, 2014; Yesil et al., 2014).

Tugtas (2014) demonstrated successful extraction of VFAs from a synthetic solution, and achieved similar mass transfer coefficients when using acidified AF leachate. Yesil et al. (2014) also demonstrated successful VFA recovery, but commented that the $\mathrm{pH}$ of the fermentation would need to be controlled to facilitate recovery of VFAs, as a low permeation rate occurs at higher $\mathrm{pH}$, as agreed upon by Plácido and Zhang (2017a). To further support bypassing the extractant step, Schlosser et al. (2005) states that "due to a slower decomposition of the extractant-acid complex on the stripping interface" the second membrane extraction step tends to have a mass transfer coefficient an order of magnitude smaller than the primary membrane extraction step. By removing the need for the decomposition of the extractant-acid complex, there should be an improvement in the overall rates of extraction in the process.

The most recent work by Aydin et al. (2018), is an extension of the initial work by Tugtas (2014) and Yesil et al. (2014). This work considers filling the pores of the membrane with an organic extractant, either TOA or tridodecylamine (TDDA), to facilitate the extraction. Combining the two-stage organic extraction and sodium hydroxide extraction process (top route, Figure 1 ) into a single stage (middle route, Figure 1) should reduce the capital cost associated with having two membrane unit operations. The use of an extractant-filled membrane is effectively the same as the liquid membrane work described by Schlosser et al. (2005) for carboxylic acids. This research, by Aydin et al (2018), demonstrates that TOA is a useful extractant for recovery of VFA and improves the selectivity of recovery compared to using an "air-filled" polytetrafluoroethylene (PTFE) membrane. The overall mass transfer coefficient for these membrane extraction systems were not provided, but the use of an extractant could reduce the overall mass transfer coefficient due to having to break the extractant-acid complex compared to the "air-filled" membrane system (Schlosser et al., 2005). This 
research state that this process is a "cost effective and environmental alternative" to other membrane extraction possibilities, but no quantitative economic analysis or life-cycle assessment relating to the use of an extractant has been provided to support this. Although the research demonstrates some advantages for this type of membrane, there are some concerns that need to be addressed before stating that this is a suitable membrane alternative for combining with a fermentation. These concerns include: feasibility of producing extractant-filled membranes on a large scale $\left(>1000 \mathrm{~m}^{2}\right)$, stability of extractant in membrane pores, potential toxicity of extractant on fermentation, and lastly, the potential fouling of the extractant.

To further reduce the number of unit operations it is proposed in this work that water can be used as an extractant, bottom route Figure 1. Although this does not facilitate a constant concentration gradient across the membrane, it should reduce both the capital and operating costs as a downstream regeneration or acidification step is not required and water is a cheap and recyclable resource compared to organic extractants or the consumed sodium hydroxide. Additionally, the acids remain in the undissociated form. Therefore, no counter ion removal is required, so no mineral salt is produced that has to be disposed of. Further support for water as an extractant can be seen in the results presented by Jeon and Lee (1989), for membrane extraction of butanol from fermentation broth. The results indicate that water as an extractant offers an equivalent degree of mass transfer compared to an organic extractant.

This work proposes a novel solvent-free membrane extraction process for the recovery of VFA from AF. A silicone membrane was used to separate the fermentation broth from the receiving water extractant. It is a commonly used commercial membrane material (Pervatech, 2018), known to be permeable to organic materials, and has widely been used for the selective separation of volatile fermentation products via pervaporation as a polydimethylsiloxane (PDMS) -based membrane (Van Hecke et al., 2015)., therefore should be applicable for the selective separation of VFAs. Additionally, silicone was chosen as it has been documented as "low-fouling" during membrane extraction 
integrated directly with the acetone butanol ethanol fermentation (Jeon and Lee, 1987; Qureshi and Maddox, 2005). AF generally has a high solids content, which is prone to fouling membranes, therefore selecting a membrane which is "low-fouling" is important. 


\section{Materials and Methods}

\subsection{Materials}

Acetic acid ( $\mathrm{HAc})$, proprionic acid ( $\mathrm{HPr})$, isobutyric acid (iHBu), butyric acid $(\mathrm{HBu})$, isovaleric acid (iHVa), valeric acid ( $\mathrm{HVa})$, hexanoic acid $(\mathrm{HHex})$, and sodium hydroxide $(\mathrm{NaOH})$ pellets were obtained from Sigma-Aldrich or Fisher at a minimum 99 wt. \% or higher purity. Sulphuric acid $\left(\mathrm{H}_{2} \mathrm{SO}_{4}\right)$ was obtained from Fisher at $96 \%$ purity. Reverse osmosis (RO) Water was produced from Thermo Scientific Barnstead RO system.

\subsection{Synthetic VFA solution}

Two synthetic VFA solutions were used. The first being $50 \mathrm{~g} \mathrm{~L}^{-1}$ total VFA with equal concentration (17.6 $\mathrm{g} \mathrm{L}^{-1}$ ) of HAc, HBu and iHVa. The second was based on the synthetic VFA solution used by Yesil et al. (2014), consisting of $6 \mathrm{~g} \mathrm{HAC} \mathrm{L}^{-1}, 6 \mathrm{~g} \mathrm{HPr} \mathrm{L}^{-1}, 2 \mathrm{~g} \mathrm{HBu} \mathrm{L}^{-1}, 2 \mathrm{~g} \mathrm{HVa} \mathrm{L}^{-1}$, and $1 \mathrm{~g} \mathrm{HHex} \mathrm{L}^{-1}$. All solutions were produced using RO water.

\subsection{Extractants}

Three extractants were used: $\mathrm{RO}$ water, $2 \mathrm{M} \mathrm{NaOH}$ and $1 \mathrm{M} \mathrm{NaOH}$, both produced using $\mathrm{RO}$ water.

\subsection{Fish fermentation}

Fish, sardines and mackerel simulated as by-catch, was fermented using anaerobic digestate as inoculum from Millbrook Wastewater Treatment plant at $37^{\circ} \mathrm{C}$ for 6 days. Fermentation $\mathrm{pH}$ was not controlled, with a starting $\mathrm{pH}$ of 7.5. Before membrane extraction, the fermentation broth (liquid phase) was separated from any undigested solids using a $1 \mathrm{~mm}$ sieve. All analysis was performed on the liquid phase of the fermentation broth, post $1 \mathrm{~mm}$ filtration. The liquid was divided into two portions, of which one was $\mathrm{pH}$ adjusted using $96 \mathrm{wt}$. $\% \mathrm{H}_{2} \mathrm{SO}_{4}$ until the $\mathrm{pH}$ was below 3 . 


\subsection{Membrane extraction}

The silicone membrane (I.D. $3.2 \mathrm{~mm}$, wall thickness $0.8 \mathrm{~mm}$, length $500 \mathrm{~mm}$, Silex Silicones Ltd) was placed inside the stirred bottle, as demonstrated in Figure 2, containing $200 \mathrm{~mL}$ of desired solution based on the experiment as described in Table 1. This bottle was mixed using a magnetic stirrer controlled at $250 \mathrm{rpm}$. This was connected to tubing from the pumped bottle, containing $200 \mathrm{~mL}$ of the desired solution, Figure 1. The pump (Watson Marlow 323, UK) was operated at $100 \mathrm{~mL} \mathrm{~min}^{-1}$, which provided mixing to the pumped liquid, therefore it was assumed both sides were well mixed. The experiment was run for 150-200 hours, with samples taken from both bottles at certain intervals for VFA analysis. Experiments were performed at laboratory temperature, the hotplate (on the mixed side) was set to $25^{\circ} \mathrm{C}$ to ensure the minimum temperature of the liquid in the membrane extraction system did not fall below $20^{\circ} \mathrm{C}$ to ensure a more consistent temperature overnight. Operating at ambient temperature was chosen to best represent scaled up conditions, where the external membrane extraction unit would most likely not be temperature controlled, relying on residual heat in the fermentation broth. Each experiment was performed in duplicate. 


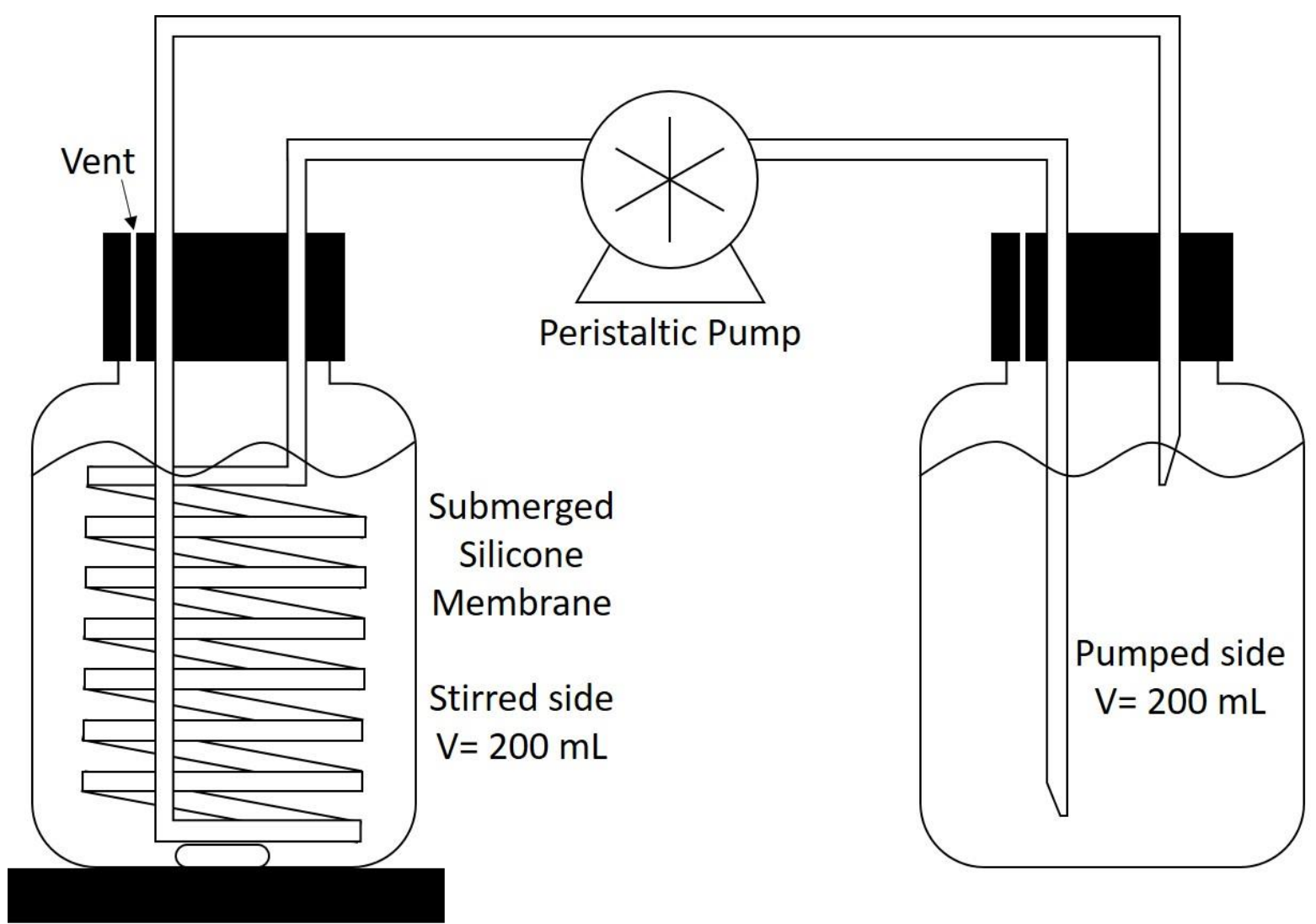

Hot plate/Stirrer

Figure 1: Schematic of the simple membrane extraction setup used to test VFA recovery

Table 1: Overview of experiments performed. Each experiment was performed in duplicate.

\begin{tabular}{|l|l|l|l|l|}
\hline \multicolumn{2}{|l|}{ Experiment } & Pumped Solution & Stirred Solution & VFA Solution pH \\
\hline $\mathbf{1}$ & Pumped VFA, Stirred $\mathrm{RO} \mathrm{H} \mathrm{H}_{2} \mathrm{O}$ & $50 \mathrm{~g} \mathrm{~L}^{-1} \mathrm{VFA}$ & RO Water & 2.5 \\
\hline $\mathbf{2}$ & Pumped VFA, Stirred $\mathrm{NaOH}$ & $50 \mathrm{~g} \mathrm{~L}^{-1} \mathrm{VFA}$ & $2 \mathrm{M} \mathrm{NaOH}$ & 2.5 \\
\hline $\mathbf{3}$ & Yesil et al. (2014) comparison & $17 \mathrm{~g} \mathrm{~L}^{-1} \mathrm{VFA}$ & $1 \mathrm{M} \mathrm{NaOH}$ & 2.5 \\
\hline $\mathbf{4}$ & Stirred VFA, Pumped RO $\mathrm{H}_{2} \mathrm{O}$ & RO Water & $50 \mathrm{~g} \mathrm{~L}^{-1} \mathrm{VFA}$ & 2.5 \\
\hline $\mathbf{5}$ & Acidified Fish Fermentation & RO Water & Fish Fermentation & 2.3 \\
\hline $\mathbf{6}$ & Unacidified Fish Fermentation & RO Water & Fish Fermentation & 6.9 \\
\hline
\end{tabular}




\subsection{Analytical methods}

$\mathrm{pH}$ was measured using a Five Easy $\mathrm{pH} / \mathrm{mV}$ meter (Mettler Toledo), with temperature compensation.

VFA concentrations were determined by liquid injection gas chromatography (Shimadzu GC-2010) with flame ionisation detector, and SGE BP-21 column $(30 \mathrm{~m}$, internal diameter $0.25 \mathrm{~mm}$, and film thickness $0.25 \mu \mathrm{m})$. The carrier gas was helium, and a split ratio of 100:1 was used. The oven temperature increased from $60^{\circ} \mathrm{C}$ to $210^{\circ} \mathrm{C}$ at a rate of $10^{\circ} \mathrm{C} \mathrm{min}{ }^{-1}$ followed by a 5 minute hold. The injector temperature was $200^{\circ} \mathrm{C}$ and the detector temperature $250^{\circ} \mathrm{C}$. Fish fermentation samples were centrifuged at $14,000 \mathrm{~g}$ for 15 minutes (VWR micro star 17), and the supernatant used for analysis. All samples were diluted to ensure the concentration was between 0 and $500 \mathrm{mg} \mathrm{L}^{-1}$ and supplemented with $10 \%$ formic acid.

The fermentation gas was collected in a gas-impermeable sampling bag. Its volume was measured using a weight-type water displacement gasometer and expressed as the volume at standard temperature $\left(0^{\circ} \mathrm{C}\right)$ and pressure ( $\left.1 \mathrm{~atm}\right)$ as described by Walker et al. (2009). The gas composition was determined using a MG \#5 GC (SRI Instruments) with a thermal conductivity detector. $\mathrm{CO}_{2}$ was isolated using a porapack-Q $80 / 100$ mesh (6ft) column and $\mathrm{H}_{2}$ was separated with a molecular sieve $5 \AA \AA$ (6ft) column. Standard methods were followed for the measurement of TAN (APHA, 2005), using a BÜCHI K-350 Distillation Unit with $\mathrm{NaOH}$ addition followed by collection of the distillate in a boric acid indicator and titration with $0.25 \mathrm{~N} \mathrm{H}_{2} \mathrm{SO}_{4}$. Standard methods were followed for the measurement of chemical oxygen demand (COD) using the closed reflux method (APHA, 2005).

Total solids (TS) and volatile solids (VS) were measured according to Standard Method 2540G (APHA, 2005) using a Heraeus Function Line Series oven and 201/301 Carbolite muffle furnace.

Total alkalinity was measured by titration with $0.25 \mathrm{~N} \mathrm{H}_{2} \mathrm{SO}_{4}$, to an endpoint of $\mathrm{pH} 4.0$, using an automatic digital titration burette system (SCHOTT titro-line easy), based on the Standard Method 2320B (APHA, 2005). 


\subsection{Calculation methods}

The flux, J, is defined as the rate of mass transfer across the membrane $\left(\mathrm{g} \mathrm{m}^{-2} \mathrm{~h}^{-1}\right)$ calculated by:

$$
J_{i}=\frac{1}{A} \frac{\Delta m_{i}}{\Delta t}
$$

Equation 1

Where $\Delta \mathrm{m}$ is the change in mass of species $i(\mathrm{~g}), \mathrm{A}$ is the membrane surface area for mass transfer $\left(\mathrm{m}^{2}\right)$ and $\Delta \mathrm{t}$ is the change in time (h). The average flux over the total experiment duration was used for the fermentation membrane extraction experiments.

The overall mass transfer coefficient, $\mathrm{K}_{\mathrm{ov}}$, is a constant used to compare membrane extraction systems. It can be described for the VFA solution (or feed, F) by:

$$
\begin{array}{cc}
J_{i}=A K_{o v}\left(C_{i, F}-C_{i, F}^{*}\right) & \text { Equation 2 } \\
\ln \left(\frac{C_{i, F}-C_{i, F}^{*}}{C_{i, F_{0}}-C_{i, F}^{*}}\right)=\frac{A K_{o v} t}{V_{F}} & \text { Equation 3 }
\end{array}
$$

Where $C$ is the concentration of $i$ in the VFA solution, * denotes equilibrium concentration, and $V_{F}$ is the initial volume of the VFA solution. $K_{o v}$ is calculated from the gradient of the line of best fit when plotting $\ln \left(\left(C_{i, F}-C_{i, F}{ }^{*}\right) /\left(C_{i, F 0}-C_{i, F}{ }^{*}\right)\right)$ against $t$. This is the same as the calculations used by Tugtas (2014), but accounts for equilibrium formation as no species transformation occurs in these experiments. For reactive extraction experiments (using sodium hydroxide as an extractant) the equilibrium concentrations are treated as 0 .

The Reynolds number, Re, was calculated via the following equations:

$$
\begin{gathered}
R e=\frac{\rho v L}{\mu} \\
R e_{N}=\frac{\rho N D_{i d}^{2}}{\mu}
\end{gathered}
$$

Where $\rho$ is the density $\left(\mathrm{kg} \mathrm{m}^{-3}\right), v$ is the velocity $\left(\mathrm{m} \mathrm{s}^{-1}\right), L$ is the characteristic length $(\mathrm{m}), \mu$ is the dynamic viscosity $\left(\mathrm{kg} \mathrm{m}^{-1} \mathrm{~s}^{-1}\right), \mathrm{Re}_{\mathrm{N}}$ is the rotational Reynolds number (for the stirred system), $\mathrm{N}$ is the rotational speed (revolutions per second). 


\section{Results and Discussion}

\subsection{VFA recovery from synthetic solution}

The novel solvent-free membrane extraction system was initially evaluated using a $50 \mathrm{~g} \mathrm{~L}^{-1}$ synthetic VFA solution containing $17.6 \mathrm{~g} \mathrm{~L}^{-1}$ acetic, butyric and isovaleric acid, as these acids were observed to be the most abundant in previous work (Plácido and Zhang, 2017a). As each experiment was performed, it was observed that the concentration in the synthetic VFA solution decreased over time, see in Supplementary Information. This demonstrated that the VFAs could successfully diffuse though the non-porous silicone membrane, as desired.

These experiments did not achieve $100 \%$ recovery after 200 hours of operation. In contrast, Plácido and Zhang (2017a) achieved nearly 100\% recovery in less than 24 hours when using a porous membrane. This is due to less resistance to mass transfer; as transport through a porous membrane is based on the solute flowing through the pores, whereas a non-porous membrane relies on fast adsorption and desorption in and out of the membrane. In preliminary tests with a porous hydrophobic polyethersulfone (PES) membrane (Spectrum Labs) and 2M sodium hydroxide extractant, the $\mathrm{pH}$ of the VFA solution rapidly increased due to hydroxide ions transporting across the membrane through the pores (data not shown). The membrane was not hydrophobic enough to maintain repulsion of the water and maintain "air-filled" pores, therefore the ions could transfer between the feed and extractant based on liquid diffusion. Transfer of the extractant was not observed with a non-porous silicone membrane, as the hydroxide ions cannot adsorb into the silicone, and the initial $\mathrm{pH}$ of synthetic VFA solution did not vary from the starting $\mathrm{pH}$.

As this is a batch system the concentration gradient varies over time, therefore the diffusion rate will also vary over time. This is because the concentration gradient provides the driving force for mass transfer, Equation 2. Comparison of the overall mass transfer coefficient takes into account the concentration driving force of the system, therefore allows a better comparison of mass transfer across different experimental conditions. To calculate the overall mass transfer coefficient the final 
data point, between 150 and 200 hours, was used to provide the equilibrium concentration. After the 150 hours of batch operation, the rate of VFA removal had significantly slowed down, therefore the experiment was near equilibrium conditions. When water was used as an extractant, the equilibrium was expected to be approximately half of the starting VFA concentration (due to equal volumes of feed and extractant). In practice, concentrations below the predicted equilibrium were observed, Table 2. It is suspected that this is related to the distribution of VFA in the silicone being greater than in the aqueous phase, therefore it is possible to remove more VFA from the feed than the predicted equilibrium point. Further work is required to better understand the affinity of VFAs for silicone.

Table 2: VFA feed concentrations exceeding the predicted equilibrium, when using water as an extractant

\begin{tabular}{|c|c|c|c|c|c|c|c|c|}
\hline & \multicolumn{4}{|c|}{ Pumped VFA, Stirred $\mathrm{RO}_{2} \mathrm{O} 1$} & \multicolumn{4}{|c|}{ Pumped VFA, Stirred $\mathrm{RO}_{2} \mathrm{O} 2$} \\
\hline & $\mathrm{HAC}$ & $\mathrm{HBu}$ & $\mathrm{iHVa}$ & Total & HAC & $\mathrm{HBu}$ & iHVa & Total \\
\hline Initial concentration $\left(\mathrm{g} \mathrm{L}^{-1}\right)$ & 18.7 & 18.7 & 19.25 & 56.7 & 16.8 & 17.2 & 17.9 & 51.9 \\
\hline Predicted equilibrium concentration $\left(\mathrm{g} \mathrm{L}^{-1}\right)$ & 9.3 & 9.3 & 9.6 & 28.3 & 8.4 & 8.6 & 8.9 & 25.9 \\
\hline End concentration, $\mathrm{t}=170 \mathrm{hrs}\left(\mathrm{g} \mathrm{L}^{-1}\right)$ & 8.7 & 5 & 3.95 & 17.7 & 9.9 & 5.7 & 4.4 & 20.0 \\
\hline
\end{tabular}

The first comparison was between the use of water and $2 \mathrm{M} \mathrm{NaOH}$ extractant. A $2 \mathrm{M}$ concentration was used to ensure that the $\mathrm{NaOH}$ was in excess, to ensure maintaining the maximum concentration gradient possible. Good repeatability was observed between duplicates, Figure 3Error! Reference source not found.. Using water as an extractant provided a faster rate of mass transfer compared to $\mathrm{NaOH}$, as demonstrated by having larger overall mass transfer coefficients. 


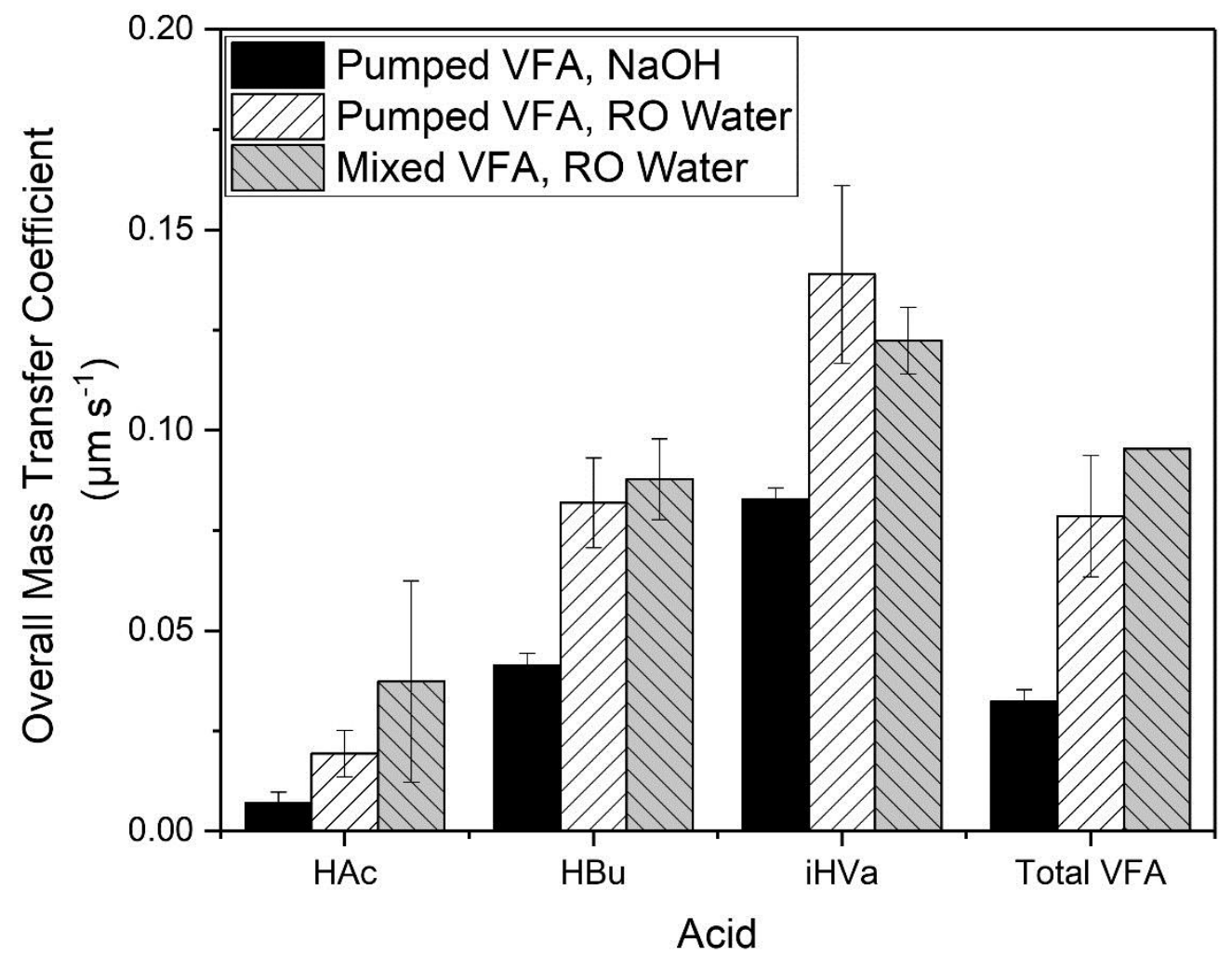

Figure 2: Comparison of the overall mass transfer coefficient with $50 \mathrm{~g}$ VFA $L^{-1}$ synthetic solution. 
In all experiments isovaleric acid had a greater mass transfer coefficient, followed by butyric acid, Figure 3. The overall mass transfer coefficient for acetic acid was typically half that of butyric and isovaleric. These results demonstrate that selective separation, based on hydrophobicity, is possible. This is interesting, as it would normally be expected that smaller molecules have a faster diffusion rate than larger molecules. In this scenario, the larger molecules are more hydrophobic due to the longer chain length, this also means that the charge density influenced by the acid structure of the molecule is lower. Therefore, the larger acids have a greater affinity with the silicone membrane compared to the water which results in faster mass transfer. This indicates that selective recovery is possible with a non-porous membrane. The total VFA overall mass transfer coefficient is lower than that of butyric and isovaleric acid, due to the lower mass transfer of acetic acid.

Based on these results, it should be possible to optimise the membrane area based on the recovery of a specific, longer-chain acid. For example, if $\mathrm{C} 4$ acids (and higher) are the desired product then the overall mass transfer of butyric acid can be used to design the membrane extraction unit. As the overall mass transfer coefficient of butyric acid is greater than acetic acid, a smaller membrane area will be required for the same percentage recovery. This will reduce the contact time for transfer of acetic acid, therefore less acetic acid should be present in the extractant which will reduce the number of acids (or impurities) to be separated in further downstream separation. This would need to be considered alongside a more appropriate (continuous) process design. The current batch membrane extraction process is not directly representative of how the process will operate when integrated with a fermentation.

These experiments also compared the impact of system setup on the mass transfer, using water as the extractant. The two setup options provide different flow regime for the VFA solution. When the VFA solution was pumped the Reynolds number was $6.63 \times 10^{14}$ (Equation 4 ), compared to $1.43 \times 10^{7}$ (Equation 5) for when it was mixed. The film mass transfer coefficients can be described as a function of the Reynolds number and Schmidt number (Prasad and Sirkar, 1992). As the Schmidt 
number will be constant for this system, and only the fluid velocity term varies in the Reynolds number. In this system, as observed in Figure 3 , there is very little difference between the two system set ups. System design is not often considered when optimising membrane extraction but this should still be considered when scaling up this process.

To provide an better comparison with literature the same synthetic solution and $\mathrm{NaOH}$ extractant as that used by Yesil et al. (2014) was used with a silicone membrane. In general, the work by Yesil et al. (2014) had a greater mass transfer coefficient, Table 3. This is not surprising as the mechanism of mass transfer, for Yesil et al. (2014), is evaporation into the gas phase, diffusion through the membrane pores, then absorption into the extractant. Whereas, in this work the mass transfer is reliant on the absorption into a solid, diffusion through it and desorption into the extractant which is inherently slower. Additionally, the membrane used by Yesil et al. (2014) was only $75 \mu \mathrm{m}$ thick, compared to the thickness of the silicone at $800 \mu \mathrm{m}$. The membrane mass transfer coefficient is inversely proportional to the membrane thickness, Equation 6 (Prasad and Sirkar, 1992).

$$
k_{m}=\frac{D_{i, e f f}}{l}
$$

Where $k_{m}$ is the membrane mass transfer coefficient, $D_{l, \text { eff }}$ is the effective diffusivity for component $i$ and $I$ is the membrane thickness $(m)$. Reducing the thickness of the silicone membrane will help increase its competitiveness in membrane systems. The slower rate of mass transfer with a silicone membrane would mean that to achieve the same removal rates as a porous membrane, a larger membrane area would be required.

Table 3: Comparison of overall mass transfer coefficient for this work and Yesil et al. (2014)

\begin{tabular}{|l|r|r|r|r|r|}
\hline & \multicolumn{5}{|c|}{ Kov $(\boldsymbol{\mu m} / \mathbf{s})$} \\
\hline & \multicolumn{1}{|c|}{ HAc } & \multicolumn{1}{|c|}{ HPr } & \multicolumn{1}{l|}{ HBu } & \multicolumn{1}{l|}{ HVa } & \multicolumn{1}{c|}{ HHex } \\
\hline This Work & 0.0017 & 0.0075 & 0.0168 & 0.0536 & 0.1991 \\
& \pm 0.0022 & \pm 0.0016 & \pm 0.0024 & \pm 0.0018 & \pm 0.0095 \\
\hline Yesil et al. (2014) & 0.5639 & 0.7139 & 0.9750 & 1.2111 & 2.0778 \\
\hline
\end{tabular}




\subsection{Fish fermentation}

Two fish fermentations were performed. One used sardines and the other mackerel. Both fermentations were run for 6 days. The end results of the fermentation are shown in Table 4. Even though different fish were used for the fermentations, the results are relatively similar and provide a good basis for comparison. In practice, it is likely that the fermentation of fish waste will constitute a multitude of species which will vary with seasons, therefore comparison of the different fish is applicable for the investigation into VFA recovery.

When comparing the VFA concentrations achieved, the total VFA concentration is similar for both fermentations, and the individual acid concentrations are also similar, Table 4 . This means that it is acceptable to directly compare the flux achieved when applying membrane extraction to the fermentation broth. 
Table 4: End of fermentation broth conditions and the impact of acidification on fermentation broth

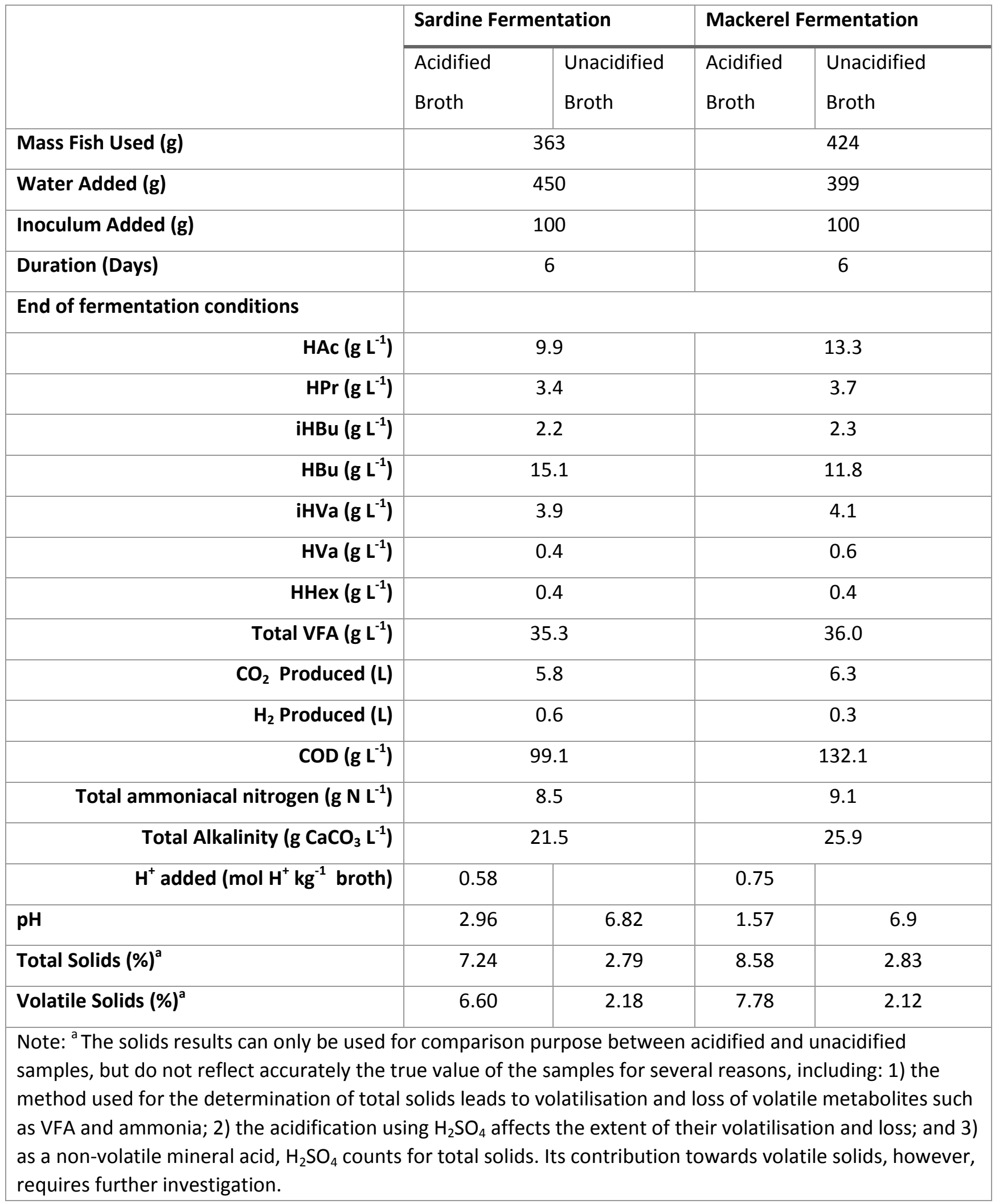




\subsection{VFA recovery from fish fermentation}

For the fermentation membrane extraction experiments, the VFA solution was placed inside the stirred bottle. This would provide an easier understanding of potential fouling by the fermentation, as any fouling would be visible when taking samples during the experiments.

It was decided to perform membrane extraction at two $\mathrm{pH}$ values - acidified $(\mathrm{pH} 2-3)$ and unacidified (pH7). This is based on the observation by Plácido and Zhang (2017a), and Yesil et al. (2014) who both state that a pH lower than the pKa of the VFAs is required for successful mass transfer. Acidification of the fermentation broth was achieved through the addition of $\mathrm{H}_{2} \mathrm{SO}_{4}$, Table 4. The acidification of the fermentation broth had a visible effect on the fermentation broth. There was a colour change, where the acidified broth turned a slightly paler brown colour compared to the unacidified broth, see Supplementary Information; this is due to oxidation of the fermentation broth by the sulphuric acid. This also saw a three times increase in measured total solids in the acidified fermentation broth compared to the unacidified fermentation, Table 4. This was caused by the addition of $\mathrm{H}_{2} \mathrm{SO}_{4}$ for acidification, by both addition of a non-volatile mineral acid and reaction with volatile broth compounds to create mineral salts. This change must be considered when transitioning from batch fermentations to continuous fermentation with integrated VFA recovery and fermentation/biomass recycling. If the broth cannot continue to be fermented after acidification (and any required neutralisation) then alternative VFA recovery methods, which do not require this step, need to be considered.

The use of a real fermentation broth, in the silicone water membrane extraction system presented here, did not appear to show any negative impact compared to the synthetic VFA solution, Figure 4. Analysis of the mass transfer coefficient for this system, actually suggested that mass transfer had been improved for longer chain VFAs in the real fermentation broth. The results also demonstrated, as expected, that very little VFAs were recovered in the unacidified fermentation broth. This agrees with existing literature that the fermentation broth will need to be acidified prior to membrane 
extraction (Plácido and Zhang, 2017a; Yesil et al., 2014). The VFA concentrations used to calculate the overall mass transfer coefficient are based on the total amount of VFA present (in both the acid and salt form). To confirm that the driving force is the concentration of free acid, the overall mass transfer coefficient based on the free butyric acid was calculated to be $0.131 \pm 0.011 \mu \mathrm{m} \mathrm{s}^{-1}$. For the acidified system the overall mass transfer coefficient for butyric acid was $0.157 \pm 0.038 \mu \mathrm{m} \mathrm{s}^{-1}$, Figure 4. These similar values confirm that it is the difference in the concentration of free acid that is detrimental to the unacidified system, and this must be overcome for efficient recovery of VFAs.

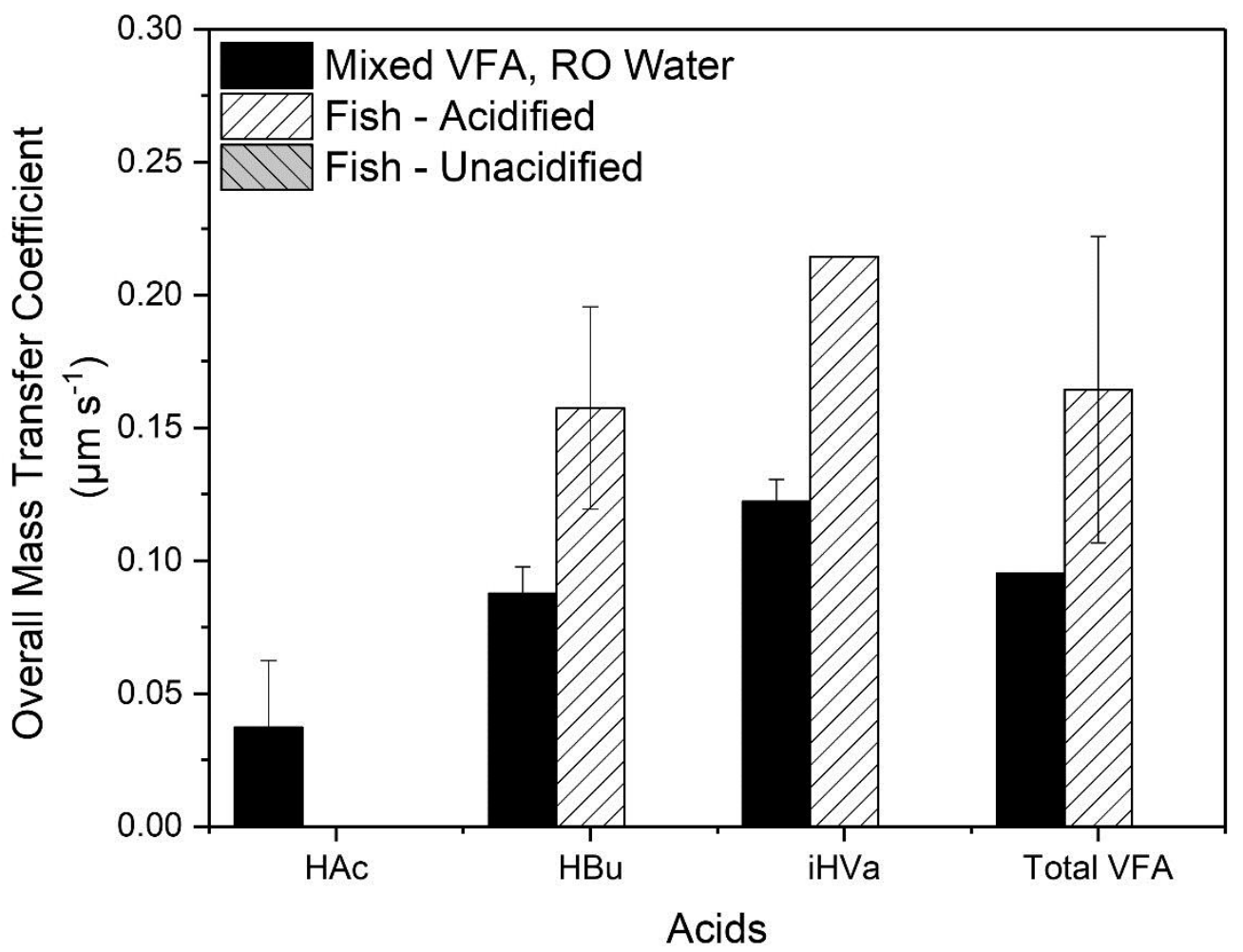

Figure 3: Comparison of the overall mass transfer coefficient for key acids for a synthetic fermentation broth, acidified and unacidified real fermentation broth

The fish fermentation had a wider range of VFAs present, Table 5, than the synthetic VFA solution used for the initial exploration of membrane extraction. In the synthetic VFA solution selective recovery for larger chain VFAs was evident. This is further confirmed by this fermentation, Table 5. Based on the results, presented in Table 5, the order of selectivity is 
$H H e x>i H V a>H V a>H B u>i H B u>H P r>H A c$, confirming that selectivity is based on hydrophobicity. When compared to other membrane extraction work combined with AF, in Table 5, only Plácido and Zhang (2017a) demonstrate similar degrees of selectivity. This is due to the use of an organic extractant, as similar selectivity observations were made in work focusing on liquid-liquid extraction (Alkaya et al., 2009; Reyhanitash et al., 2016). The use of an aqueous solution with porous membrane does not provide selectivity (Aydin et al., 2018), thereby all selectivity would be driven by fermentation optimisation towards a specific acid. 
Table 5: Comparison of all membrane extraction work combined with acidogenic fermentation

\begin{tabular}{|c|c|c|c|c|c|c|c|c|c|c|c|c|}
\hline \multirow[t]{2}{*}{ Reference } & \multirow{2}{*}{$\begin{array}{l}\text { Fermentation } \\
\text { Feedstock }\end{array}$} & \multirow[t]{2}{*}{ Membrane } & \multirow[t]{2}{*}{ Extractant } & \multirow{2}{*}{$\begin{array}{l}\text { Broth } \\
\text { pH }\end{array}$} & \multirow{2}{*}{$\begin{array}{l}\text { Recovery } \\
\text { pH }\end{array}$} & \multicolumn{7}{|c|}{ Overall Mass Transfer Coefficient $(\mu \mathrm{m} / \mathrm{s})$} \\
\hline & & & & & & HAC & HPr & iHBu & $\mathrm{HBu}$ & iHVa & $\mathrm{HVa}$ & HHex \\
\hline This Work & \multirow[t]{2}{*}{ Fish } & $\begin{array}{l}\text { Non-porous } \\
\text { Silicone }\end{array}$ & Water & 6.9 & 2.3 & $\begin{array}{l}0.000 \\
\pm 0.000\end{array}$ & $\begin{array}{l}0.114 \\
\pm 0.041\end{array}$ & $\begin{array}{l}0.175 \\
\pm 0.012\end{array}$ & $\begin{array}{l}0.157 \\
\pm 0.038\end{array}$ & $\begin{array}{l}0.214 \\
\pm 0.000\end{array}$ & $\begin{array}{l}0.209 \\
\pm 0.066\end{array}$ & $\begin{array}{l}0.144 \\
\pm 0.092\end{array}$ \\
\hline This Work & & $\begin{array}{l}\text { Non-porous } \\
\text { Silicone }\end{array}$ & Water & 6.9 & 6.9 & $\begin{array}{l}0.000 \\
\pm 0.000\end{array}$ & $\begin{array}{l}0.000 \\
\pm 0.000\end{array}$ & $\begin{array}{l}0.000 \\
\pm 0.000\end{array}$ & $\begin{array}{l}0.000 \\
\pm 0.000\end{array}$ & $\begin{array}{l}0.000 \\
\pm 0.000\end{array}$ & $\begin{array}{l}0.000 \\
\pm 0.000\end{array}$ & $\begin{array}{l}0.000 \\
\pm 0.000\end{array}$ \\
\hline Yesil et al. (2014) & OFMSW & Porous PTFE & $\mathrm{NaOH}$ & 6.6 & 6.6 & 0.003 & 0.004 & 0.000 & 0.022 & 0.000 & 0.021 & 0.022 \\
\hline Tugtas (2014) & MSW & Porous PTFE & $\mathrm{NaOH}$ & & 3 & $\begin{array}{l}0.639 \\
\pm 0.014\end{array}$ & $\begin{array}{l}0.750 \\
\pm 0.139\end{array}$ & $\begin{array}{l}0.139 \\
\pm 0.028\end{array}$ & $\begin{array}{l}1.444 \\
\pm 0.083\end{array}$ & $\begin{array}{l}0.023 \\
\pm 0.002\end{array}$ & $\begin{array}{l}0.639 \\
\pm 0.056\end{array}$ & $\begin{array}{l}0.861 \\
\pm 0.139\end{array}$ \\
\hline $\begin{array}{l}\text { Plácido and Zhang } \\
(2017 a)^{1}\end{array}$ & \multirow[t]{2}{*}{ Freeze dried blood } & Porous PP & $\begin{array}{l}\text { TOA + 1- } \\
\text { Octanol }\end{array}$ & & Acidified & 0.058 & 0.170 & 0.156 & 0.291 & 0.325 & 0.000 & 0.145 \\
\hline $\begin{array}{l}\text { Plácido and Zhang } \\
\text { (2017a) })^{1}\end{array}$ & & Porous PP & $\begin{array}{l}\text { TOA + 1- } \\
\text { Octanol }\end{array}$ & & Unacidified & 0.099 & 0.121 & 0.084 & 0.091 & 0.085 & 0.027 & 0.091 \\
\hline Aydin et al. (2018) & Landfill leachate & $\begin{array}{l}\text { PTFE-TOA } \\
\text { filled }\end{array}$ & $\mathrm{NaOH}$ & 5.6 & 4 & \multirow{3}{*}{\multicolumn{7}{|c|}{ Not provided }} \\
\hline Aydin et al. (2018) & $\begin{array}{l}\text { Fermentation broth } \\
\text { (OFMSW) }\end{array}$ & $\begin{array}{l}\text { PTFE-TOA } \\
\text { filled }\end{array}$ & $\mathrm{NaOH}$ & 4.6 & 4 & & & & & & & \\
\hline Aydin et al. (2018) & $\begin{array}{c}\text { Chicken Manure } \\
\text { digestate }\end{array}$ & $\begin{array}{l}\text { PTFE-TOA } \\
\text { filled }\end{array}$ & $\mathrm{NaOH}$ & 8.2 & 4 & & & & & & & \\
\hline \multicolumn{13}{|c|}{$\begin{array}{l}{ }^{1} \text { Calculated from provided data set (Plácido and Zhang, 2017b) } \\
\text { OFMSW - Organic fraction of municipal solid waste } \\
\text { MSW - Municipal solid waste } \\
\text { PTFE - polytetrafluoroethylene }\end{array}$} \\
\hline
\end{tabular}


Table 5 also shows the overall mass transfer coefficients for each acid are generally comparable to existing literature. Yesil et al. (2014) and Tugtas (2014) both used a leachbed reactor, so the coarse solids would have been retained in the reactor. The unacidified results from Yesil et al. (2014) could be considered as negligible mass transfer occurred, this is the same as the results achieved in this work. Due to the need to acidify the fermentation broth, an external membrane extraction unit would be required. Plácido and Zhang (2017a), used the same inoculum from the same source as this work but with a different feedstock and applied greater clarification to the fermentation broth prior to recovery. The results between their work and this work are very similar, and follow the same selective trend. This is surprising considering that previous results indicated that mass transfer with a non-porous membrane is two orders of magnitude slower than with a porous membrane, Table 3 . It must be noted that there is an expectation that the mass transfer coefficient, for this work, has the potential to increase further if a thinner membrane is used. Therefore, for the process proposed in this work, the elimination of an expensive or consumable extractant should help the economic viability.

In literature, it is assumed that fouling is responsible for the decrease in mass transfer coefficient when transitioning from a synthetic VFA solution to real fermentation broth. Yesil et al. (2014), observed the overall mass transfer coefficient decrease by an order of 2. In this work, the overall mass transfer coefficients for all acids are of the same order for both the synthetic solution and the acidified fish fermentation. This can be related to the minimal fouling of the membrane that was observed after 200 hours of operation. The acidified fermentation broth had more visible fouling, see Supplementary Information, but as already discussed, there was a higher solids content likely to be from proteins and other soluble material which precipitated on acidification. This fouling is easily removed by rinsing with water (see Supplementary Information), therefore should have minimal impact on extraction process. All other researchers used a porous membrane, and it is generally assumed that the reduction in mass transfer between a synthetic and real fermentation broth is due to the solids content. Only Aydin et al. (2018) provided the \% total solid content for their 
fermentation broths: landfill leachate, 1.90\%; OFMSW fermentation broth, 1.50\%; chicken manure and poppy straw digestate, $5.66 \%$. The OFMSW fermentation broth is likely to be representative of the broth used by Yesil et al. (2014) and Tugtas (2014). It is assumed that these are representative of the fermentation broth prior to acidification and the values are not too dissimilar from those observed in the fish fermentation, Table 4. As our results, Figure 3, have not shown a decrease in the overall mass transfer coefficient suggests that using a non-porous silicone membrane may be advantageous for fermentation broths with a high solid content.

As the fermentation broth is a complex mixture, analysis was performed on the extractant to see if any unaccounted species were being extracted across the membrane. With other membrane extraction processes, analysis of the extractant has not been performed (Aydin et al., 2018; Plácido and Zhang, 2017a; Tugtas, 2014; Yesil et al., 2014). Table 4 provides further information on the $\% C O D$ of the feed and extractant that are associated with VFA and the total ammoniacal nitrogen in both the feed and the extractant. Firstly, in the 200 hour membrane extraction operation, not all the VFAs were extracted from either fermentation as $40-45 \%$ of the COD in the fermentation broth is accounted for by the VFAs. $69-74 \%$ of the COD in the extractant is accounted for by the VFAs. This indicates that other organic compounds are also being extracted from the fermentation. On further analysis of the GC chromatogram additional peaks are present, and some appear to behave in a similar manner to the VFAs therefore suggesting additional acid products are present. This unaccounted for COD could be small hydrolysed monomers from proteins or other organic fish material, it could also be other biologically produced chemicals but further analysis is required to understand this. For further downstream processing of VFAs it would be ideal for the extractant to contain minimal impurities, fortunately other small molecules known to be present in the fermentation broth such as ammonia/ammonium do not appear to transfer across the membrane. If these are other acid-type compounds, as suspected, as they are only found in the extractant from the acidified fermentation experiment then it is likely that they would also be removed via other membrane extraction configurations. 


\subsection{Membrane extraction economics}

The results so far have demonstrated that a simple membrane extraction system using a readily available silicone membrane with a simple extractant of water is able to successfully extract VFA from an acidified fermentation broth. This system also produces similar mass transfer coefficients to more complex systems using reactive extractants, which looked more favourable when comparing the mass transfer with a synthetic VFA solution. To further validate the use of a non-porous silicone membrane with water as an extractant and simple economic assessment of the membrane and extractant has been performed. This assessment had been based on the fermentation results presented in this work, and focused designing a membrane for the selective extraction of butyric acid, as this along with acetic acid were the most abundant VFAs produced in the fermentation. A VFA productivity of $5.9 \mathrm{~g} \mathrm{VFA} \mathrm{L}^{-1}$ day $^{-1}$ was assumed (based on the results in Table 4); with the aim of the VFA flux across the membrane being equal to the VFA productivity, therefore a steady state fermentation concentration is achieved. For the two reactive extractant methods, the concentration driving force was assumed to be equal to the fermentation broth, and the extractant volume was calculated to ensure it is present in excess, therefore 1.5 times the mols of acid in the fermentation broth were available in the extractant. For water as an extractant, the volume of extractant was assumed equal to the fermentation volume; therefore, for simplicity the concentration driving force was calculated based on an equal distribution of VFA between the fermentation broth and extractant. In practice further analysis of the distribution coefficients of individual VFAs between the fermentation broth, silicone membrane and aqueous extractant is required. Additionally, further research is also required to understand the optimum fermentation:extractant ratio. The results are presented in Table 6, the results have been calculated on the basis of per $L$ of fermentation broth $\left(L_{\text {ferm }}\right)$. 
Table 6: Economic analysis of membrane and extractant cost

\begin{tabular}{|c|c|c|c|c|c|c|c|c|}
\hline $\begin{array}{l}\text { Acidified } \\
\text { Fermentation }\end{array}$ & Membrane & Extractant & $\begin{array}{l}\text { Calculated } \\
\text { butyric acid } \\
\text { flux } \\
\left(\mathrm{g} \mathrm{h}^{-1} \mathrm{~m}^{-2}\right)^{a}\end{array}$ & $\begin{array}{l}\text { Estimated } \\
\text { membrane area } \\
\text { per fermentation } \\
\text { volume } \\
\left(\mathrm{m}^{2} \mathrm{~L}_{\mathrm{ferm}}{ }^{-1}\right)\end{array}$ & 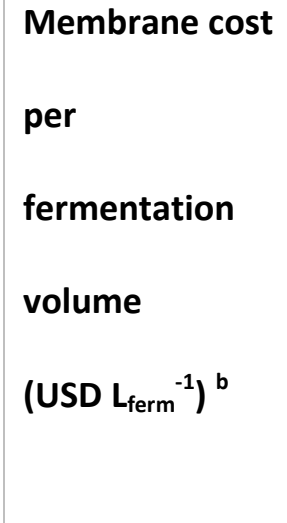 & $\begin{array}{l}\text { Extractant } \\
\text { cost } \\
\text { (USD/ } \\
\text { Lextractant) }\end{array}$ & $\begin{array}{l}\text { Volume of } \\
\text { extractant } \\
\text { required per } \\
\text { volume of } \\
\text { reactor } \\
\left(\mathrm{L}_{\text {extractant }} \mathrm{L}_{\mathrm{ferm}}{ }^{-1}\right)\end{array}$ & 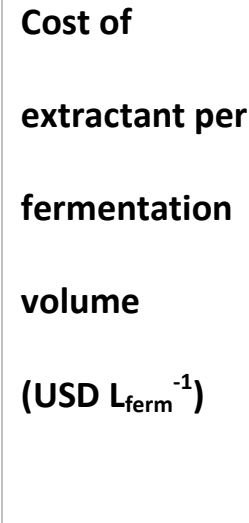 \\
\hline This Work & Silicone & Water & 0.09 & 24.3 & 7602 & $0.0005^{c}$ & 1.00 & 0.0005 \\
\hline Tugtas (2014) & $\begin{array}{l}\text { Porous } \\
\text { PTFE }\end{array}$ & $2 \mathrm{M} \mathrm{NaOH}$ & 1.68 & 1.3 & 415 & $0.063^{d}$ & 0.35 & 0.022 \\
\hline $\begin{array}{l}\text { Plácido and } \\
\text { Zhang (Plácido } \\
\text { and Zhang, } \\
\text { 2017b) }\end{array}$ & Porous PP & $\begin{array}{l}20 \% \text { TOA in } \\
1 \text {-Octanol }\end{array}$ & 0.34 & 6.6 & 2057 & $5.66^{d}$ & 1.51 & 8.54 \\
\hline
\end{tabular}

${ }^{a}$ Calculated using Equation 2 and the overall mass transfer coefficient for butyric acid provided in Table 5

${ }^{\mathrm{b}}$ Calculated using membrane cost data provided by Oudshoorn et al. (2010)

c (Towler and Sinnott, 2013)

d (Alibaba, 2018) 
As discussed in the VFA recovery from a synthetic VFA solution results (Section 3.1), the use of a non-porous membrane does require a larger membrane area, hence a greater cost. This is predominantly due to the reduced concentration driving force as the system cannot achieve $100 \%$, only reaching an equilibrium. This equilibrium-based driving force can be maximised through using a greater volume of water extractant but this will increase the complexity of any further downstream steps as the VFAs will be more dilute. This greater cost has the potential to be split over a greater period of time compared to the porous membranes as no decrease in performance was noticed due to fouling. More research is required into how long a membrane can be operated for under real fermentation broth conditions. It must also be noted that this is based on a non-optimised system, it is fully anticipated that the overall mass transfer coefficient can be improved through better system configuration, flow rate optimisation and the use of a thinner membrane. This would then allow for a reduction in membrane area, reducing the membrane cost and improving the economic competitiveness of this solvent-free membrane extraction process.

When comparing the cost of the extractants the use of process water is considerably cheaper than the other extractants. Additionally, following extraction, the VFA-water solution can be concentrated and the recovered water can be recycled through the membrane process. Using an organic extractant mixture would have the largest initial cost outlay, but as the VFA is removed from the extractant (see Figure 1) the extractant can be recycled for further processing. Assuming the membrane maintains good phase separation the extractant should not get fouled, the extractant should not need to be replaced frequently. In contrast, $\mathrm{NaOH}$ is consumed and cannot be regenerated (Figure 1), and whilst it is cheaper than the organic extractant, it is still 126 times more expensive than water. Depending on how often the membrane has to be replaced due to fouling and the limited selectivity of the porous, $\mathrm{NaOH}$ membrane extraction system, water with a non-porous membrane has the potential to be an economically favourable option for VFA recovery from mixed culture AF. 


\section{Conclusions}

Membrane extraction of VFAs from fermentation can be simplified by using a silicone membrane and water as an extractant. This would simplify the primary product recovery step, producing a free acid VFA-water solution for concentration. When combined with fermentation broth the results indicated that selective VFA recovery, at equivalent rates to porous membranes with an organic extractant is possible, with no negative impact from the presence of solids or other fermentation components. Further development is required to establish how to integrate the acidification and membrane extraction steps with the fermentation, whilst not having a negative impact.

E-supplementary information includes figures showing the VFA concentration profile, fermentation broth comparison and membrane fouling.

\section{Acknowledgements}

This work was funded by Newton Fund Institutional Links grant (275880329: 'Development of a biorefinery system for organic acid production, bioenergy generation and nutrient recovery using fish wastes from Tumaco, Colombia') delivered by the British Council. Thanks to Dr. Bing Tao for providing assistance with performing the analysis of the fermentation broth. Data supporting this study are openly available from the University of Southampton repository at http://doi.org/10.5258/SOTON/xxxxxx.

\section{References}

Alkaya, E., Kaptan, S., Ozkan, L., Uludag-Demirer, S., Demirer, G.N., 2009. Recovery of acids from anaerobic acidification broth by liquid-liquid extraction. Chemosphere, 77, 1137-1142.

APHA, 2005. Standard methods for the examination of water \& wastewater., 21st ed. American Public Health Association, Washington, DC.

Aydin, S., Yesil, H., Tugtas, A.E., 2018. Recovery of mixed volatile fatty acids from anaerobically fermented organic wastes by vapor permeation membrane contactors. Bioresource Technology, 250, 548-555.

Bekatorou, A., Dima, A., Tsafrakidou, P., Boura, K., Lappa, K., Kandylis, P., Pissaridi, K., Kanellaki, M., Koutinas, A.A., 2016. Downstream extraction process development for recovery of organic acids from a fermentation broth. Bioresource Technology, 220, 34-37. 
Chen, Y., Cheng, J.J., Creamer, K.S., 2008. Inhibition of anaerobic digestion process: A review. Bioresource Technology, 99, 4044-4064.

Jeon, Y.J., Lee, Y.Y., 1989. In situ product separation in butanol fermentation by membrane-assisted extraction. Enzyme and Microbial Technology, 11, 575-582.

Jeon, Y.J., Lee, Y.Y., 1987. Membrane-Assisted Extractive Butanol Fermentation. Annals of the New York Academy of Sciences, 506, 536-542.

Jones, R.J., Massanet-Nicolau, J., Guwy, A., Premier, G.C., Dinsdale, R.M., Reilly, M., 2015. Removal and recovery of inhibitory volatile fatty acids from mixed acid fermentations by conventional electrodialysis. Bioresource Technology, 189, 279-284.

Kleerebezem, R., Joosse, B., Rozendal, R., Van Loosdrecht, M.C.M., 2015. Anaerobic digestion without biogas? Reviews in Environmental Science and Bio/Technology, 14, 787-801.

Lee, W.S., Chua, A.S.M., Yeoh, H.K., Ngoh, G.C., 2014. A review of the production and applications of waste-derived volatile fatty acids. Chemical Engineering Journal, 235, 83-99.

Longo, S., Katsou, E., Malamis, S., Frison, N., Renzi, D., Fatone, F., 2015. Recovery of volatile fatty acids from fermentation of sewage sludge in municipal wastewater treatment plants. Bioresource Technology, 175, 436-444.

Oudshoorn, A., van den Berg, C., Roelands, C.P.M., Straathof, A.J.J., van der Wielen, L.A.M., 2010. Short-cut calculations for integrated product recovery options in fermentative production of bio-bulk chemicals. Process Biochemistry, 45, 1605-1615.

Pervatech, 2018. Membranes. http://pervaporation-membranes.com/products/membranes/ (accessed 6.5.18).

Plácido, J., Zhang, Y., 2017a. Evaluation of Esterification and Membrane Based Solvent Extraction as Methods for the Recovery of Short Chain Volatile Fatty Acids from Slaughterhouse Blood Anaerobic Mixed Fermentation. Waste and Biomass Valorization,.

Plácido, J., Zhang, Y., 2017b. Dataset for article - Esterification and membrane based solvent extraction for VFA recovery. https://doi.org/10.5258/SOTON/D0058

Prasad, R., Sirkar, K.K., 1992. Membrane-Based Solvent Extraction. Springer US, Boston, MA, pp. 727-763.

Qureshi, N., Maddox, I.S., 2005. Reduction in butanol inhibition by perstraction: Utilization of concentrated lactose/whey permeate by Clostridium acetobutylicum to enhance butanol fermentation economics. Food and Bioproducts Processing, 83, 43-52.

Rebecchi, S., Pinelli, D., Bertin, L., Zama, F., Fava, F., Frascari, D., 2016. Volatile fatty acids recovery from the effluent of an acidogenic digestion process fed with grape pomace by adsorption on ion exchange resins. Chemical Engineering Journal, 306, 629-639.

Reyhanitash, E., Kersten, S.R.A., Schuur, B., 2017. Recovery of Volatile Fatty Acids from Fermented Wastewater by Adsorption. ACS Sustainable Chemistry \& Engineering, 5, 9176-9184.

Reyhanitash, E., Zaalberg, B., Kersten, S.R.A., Schuur, B., 2016. Extraction of volatile fatty acids from fermented wastewater. Separation and Purification Technology, 161, 61-68.

Saboe, P.O., Manker, L.P., Michener, W.E., Peterson, D.J., Brandner, D.G., Deutch, S.P., Kumar, M., Cywar, R.M., Beckham, G.T., Karp, E.M., 2018. In situ recovery of bio-based carboxylic acids. Green Chemistry,

Schlosser, Š., Kertész, R., Marták, J., 2005. Recovery and separation of organic acids by membranebased solvent extraction and pertraction. Separation and Purification Technology, 41, 237-266.

Singhania, R.R., Patel, A.K., Christophe, G., Fontanille, P., Larroche, C., 2013. Biological upgrading of volatile fatty acids, key intermediates for the valorization of biowaste through dark anaerobic fermentation. Bioresource Technology, 145, 166-174.

Stark, D., von Stockar, U., 2003. In situ product removal (ISPR) in whole cell biotechnology during the last twenty years. Springer Berlin Heidelberg, pp. 149-175.

Straathof, A.J.J., 2014. Transformation of Biomass into Commodity Chemicals Using Enzymes or Cells. Chemical Reviews, 114, 1871-1908.

Tao, B., Passanha, P., Kumi, P., Wilson, V., Jones, D., Esteves, S., 2016. Recovery and concentration of 
thermally hydrolysed waste activated sludge derived volatile fatty acids and nutrients by microfiltration, electrodialysis and struvite precipitation for polyhydroxyalkanoates production. Chemical Engineering Journal, 295, 11-19.

Tugtas, A.E., 2014. Recovery of volatile fatty acids via membrane contactor using flat membranes: Experimental and theoretical analysis. Waste Management, 34, 1171-1178.

Van Hecke, W., Kaur, G., De Wever, H., 2014. Advances in in-situ product recovery (ISPR) in whole cell biotechnology during the last decade. Biotechnology Advances, 32, 1245-1255.

Van Hecke, W., Vandezande, P., Dubreuil, M., Uyttebroek, M., Beckers, H., De Wever, H., 2015. Biobutanol production from $\mathrm{C} 5 / \mathrm{C} 6$ carbohydrates integrated with pervaporation: experimental results and conceptual plant design. Journal of Industrial Microbiology \& Biotechnology, 43, 112.

Walker, M., Zhang, Y., Heaven, S., Banks, C., 2009. Potential errors in the quantitative evaluation of biogas production in anaerobic digestion processes. Bioresource Technology, 100, 6339-6346.

Yesil, H., Tugtas, A.E., Bayrakdar, A., Calli, B., 2014. Anaerobic fermentation of organic solid wastes: volatile fatty acid production and separation. Water Science and Technology, 69, 2132-2138.

Zacharof, M.-P., Mandale, S.J., Williams, P.M., Lovitt, R.W., 2016. Nanofiltration of treated digested agricultural wastewater for recovery of carboxylic acids. Journal of Cleaner Production, 112, 4749-4761.

Zhou, M., Yan, B., Wong, J.W.C., Zhang, Y., 2018. Enhanced volatile fatty acids production from anaerobic fermentation of food waste: A mini-review focusing on acidogenic metabolic pathways. Bioresource Technology, 248, 68-78.

\section{Figure Captions}

Figure 1: A high level process schematic for various membrane based recovery methods, with the intention of individual VFA recovery.

Figure 2: Schematic of the simple membrane extraction setup used to test VFA recovery

Figure 3: Comparison of the overall mass transfer coefficient with $50 \mathrm{~g} \mathrm{VFA} \mathrm{L}^{-1}$ synthetic solution.

Figure 4: Comparison of the overall mass transfer coefficient for key acids for a synthetic fermentation broth, acidified and unacidified real fermentation broth

\section{Table Captions}

Table 1: Overview of experiments performed. Each experiment was performed in duplicate.

Table 2: VFA feed concentrations exceeding the predicted equilibrium, when using water as an extractant

Table 3: Comparison of overall mass transfer coefficient for this work and Yesil et al. (2014)

Table 4: End of fermentation broth conditions and the impact of acidification on fermentation broth 
Table 5: Comparison of all membrane extraction work combined with acidogenic fermentation

Table 6: Economic analysis of membrane and extractant cost 